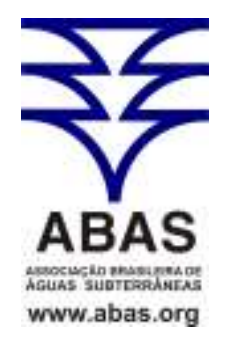

\section{DIAGNÓSTICO DA QUALIDADE DAS ÁGUAS SUBTERA- NEAS E ELABORAÇÃ̃O DO MAPA DE USO E OCUPAÇÃO DOS SOLOS NA REGIÃO DE IRECÊ-BA}

\author{
DIAGNOSIS OF QUALITY OF GROUNDWATER AND ELABORA- \\ TION OF LAND USE IN THE REGION OF IRECÊ-BA
}

\author{
Tereza Cristina Bittencourt Villanueva ${ }^{1}$, Luiz Rogério Bastos \\ Leal $^{2}$, Maria do Rosario Zucchi ${ }^{3}$, Expedito Gomes de Azevedo ${ }^{4}$, Pablo \\ Ramosandrade Villanueva ${ }^{5}$
}

Artigo recebido em: 09/07/2014 e aceito para publicação em: 24/11/2014

DOI: http://dx.doi.org/10.14295/ras.v29i1.27932

\begin{abstract}
The study area is located in the micro region of Irecê, located in the north central part of Bahia state, including a pilot area of the Salitre karst aquifer bounded in the municipalities of Irecê and Lapão. Makes a total area of approximately $250 \mathrm{~km}^{2}$ and is composed of carbonate rocks of Neoproterozoic age Salitre karst aquifer Formation. This geological unit is the karst aquifer saltpeter, which is the main source of water for irrigation purpose. It was performed a risk assessment of soil salinization and sodification through a study of quality of groundwater used for irrigation, with analysis of physicochemical elements 40 and 32 semi-volatile compounds. Particle size analysis was also performed and metals in the soil and prepare the Map Land Use of Soil and Slope Map of the area to assess the most favorable areas for agriculture. The analysis of the water used for irrigation purpose has shown that the two campaigns made, $89 \%$ of groundwater analyzed were classified as $C_{3} S_{1}$ and can normally be used for irrigation projects and only $11 \%$ of samples were classified as $\mathrm{C}_{4} \mathrm{~S}_{1}$, which waters are not to be used for irrigation, because of the danger of salinization of soil.
\end{abstract}

Keywords: Hydrochemistry. Salitre karst aquifer. Map of Land Use.

Resumo: A área de estudo localiza-se na microrregião de Irecê, situada na região centro-norte do estado da Bahia, compreendendo uma área piloto do aquífero cárstico Salitre delimitada em parte dos municípios de Irecê e Lapão. Perfaz uma área total de aproximadamente $250 \mathrm{~km}^{2}$, sendo constituída por rochas carbonáticas da Formação Salitre de idade Neoproterozóica. Esta unidade geológica constitui o aquífero cárstico Salitre, o qual é a principal fonte de suprimento hídrico para a finalidade de irrigação. Foi efetuada uma avaliação do risco de salinização e sodificação dos solos através de um estudo de qualidade das águas subterrâneas utilizadas para irrigação, com análise de 40 elementos físico-químicos e 32 compostos semi-voláteis. Foi realizada também análise granulométrica e de metais nos solos e elaboração do Mapa de Uso e Ocupação dos Solos e do Mapa de Declividade da área de forma a avaliar as áreas mais favoráveis para a atividade agrícola. A análise da água utilizada para a finalidade de irrigação permitiu constatar que nas duas campanhas efetuadas, $89 \%$ das águas subterrâneas analisadas foram classificadas como $\mathrm{C}_{3} \mathrm{~S}_{1}$, podendo ser utilizadas para projetos de irrigação e apenas $11 \%$ das amostras analisadas foram classificadas como $\mathrm{C}_{4} \mathrm{~S}_{1}$, que são águas que não devem ser utilizadas para irrigação, em função do perigo de salinização dos solos.

Palavras-Chave: Hidroquímica. Aquífero cárstico Salitre. Mapa de Uso e Ocupação dos Solos.

\footnotetext{
${ }^{1}$ Pesquisadora em Geociências do Serviço Geológico do Brasil - CPRM (tereza.villanueva@ cprm.gov.br).

2 Professor Associado do Instituto de Geociências da Universidade Federal da Bahia (lrogerio@ufba.br).

${ }^{3}$ Professora do Instituto de Física da Universidade Federal da Bahia (maria.zucchi@ gmail.com).

${ }^{4}$ Professor do Instituto de Física da Universidade Federal da Bahia (expedito@ufba.br).

${ }^{5}$ Analista Ambiental do Ministério do Meio Ambiente (pablo.villanueva@mma.gov.br).
} 



\section{INTRODUÇÃO}

A qualidade da água para irrigação é determinada por meio da análise de diversas variáveis físico-químicas e constitui uma etapa importante para o planejamento e gestão agrícola de uma área. $\mathrm{O}$ conhecimento das características qualitativas pode contribuir na tomada de decisões sobre o uso adequado dos recursos hídricos.

A água utilizada para a irrigação deve ser bem avaliada, pois como constatado por Ayres \& Westcot, (1985), mesmo com baixa concentração iônica, pode ocasionar problemas de salinização e sodificação do solo, caso não seja manejada corretamente.

A salinidade das águas subterrâneas depende, sobretudo, da sua origem, da composição e facilidade de dissolução do substrato em que se encontra em contato, ou seja, da geologia da região (Yaron, 1973), bem como das características climáticas da região na qual circula. Os valores de pH tendem a ser mais elevados em função da presença de carbonatos e bicarbonatos na água. Eaton (1949) constatou que quando essa água é utilizada para irrigação, pode promover a precipitação do cálcio, na forma de carbonato de cálcio, facilitando o processo de sodificação do solo.

A relação de adsorção de sódio (RAS) da água de irrigação pode ser utilizada como uma medida do risco de sodicidade, visto que esta pode ser correlacionada com a RAS do solo após atingido o equilíbrio dinâmico. Entretanto, a classificação da água de irrigação de acordo com o risco de problemas de infiltração de água no solo, deve ser efetuada com base na RAS e na condutividade elétrica (C.E.) da água de irrigação, levan- do-se em conta que quanto maior for a salinidade da água, menor será o efeito dispersante do sódio, ou seja, os sais presentes na solução do solo têm efeito floculante, aumentando a infiltração (AYRES \& WESTCOT,1985).

O trabalho objetiva realizar uma análise hidroquímica e de metais no solo na região de Irecê, de forma a avaliar a qualidade das águas subterrâneas e dos solos na área, além de efetivar a elaboração do Mapa de Uso e Ocupação dos Solos, para possibilitar um melhor gerenciamento desses recursos por parte do poder público municipal e estadual.

\section{CARACTERIZAÇÃO DA ÁREA}

\section{Localização e Geologia}

A área de pesquisa é formada por um polígono que compreende parte dos municípios de Irecê e Lapão, no estado da Bahia, com uma área de aproximadamente $250 \mathrm{~km}^{2}$ (Figura 1), (NOSSA, 2011).

A litologia é formada por rochas essencialmente carbonáticas (calcilutitos, calcissiltitos, calcarenitos, dolomitos, lamitos algais e margas) da Formação Salitre de idade Neoproterozóica, caracterizada como paleoambiente deposicional continental e marinho de águas rasas (Pedreira et al., 1987), com feições cársticas bem desenvolvidas, que juntamente com zonas de fraturamento, constituem os reservatórios de grande expressividade do ponto de vista de recepção, armazenamento e circulação de águas subterrâneas.

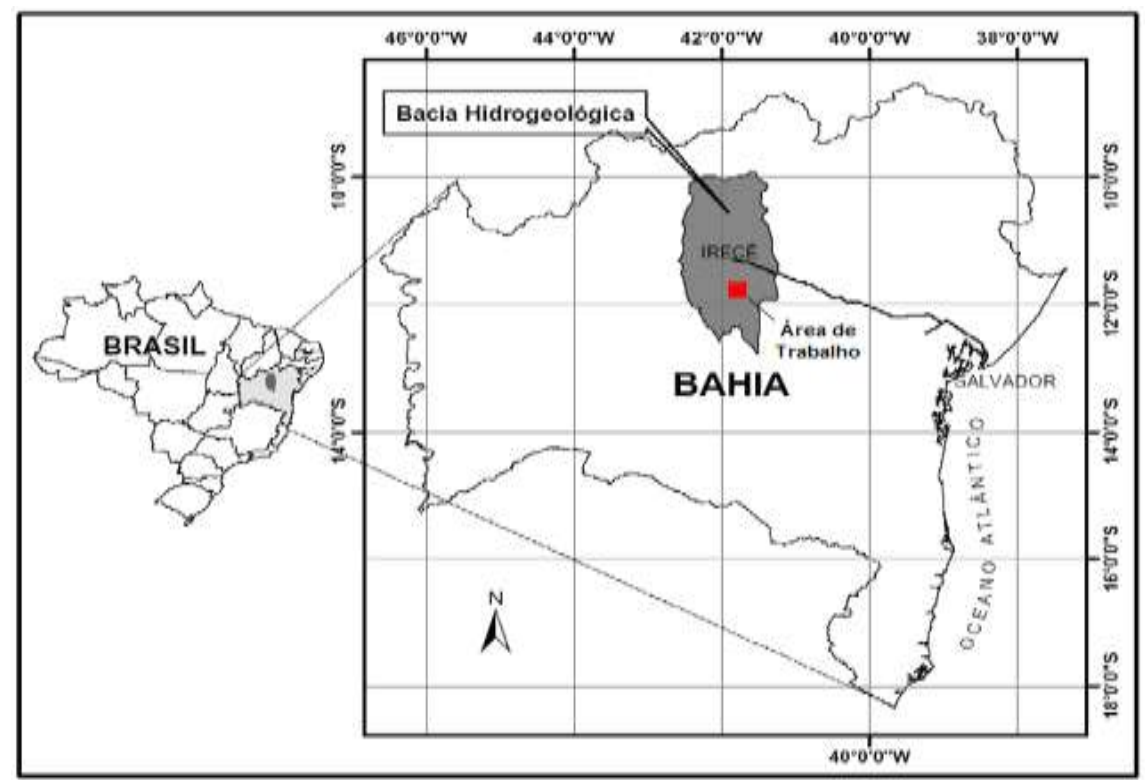

Figura 1- Mapa de localização da área 


\section{Balanço hídrico-climatológico}

O balanço hídrico-climatológico é uma das várias maneiras de se monitorar a variação do armazenamento de água no solo, a partir do suprimento de água ao solo, via precipitação ou irrigação, da demanda atmosférica e da capacidade de água disponível, o balanço hídrico fornece estimativas da evapotranspiração real, da deficiência, do excedente hídrico e do armazenamento de água no solo. $\mathrm{O}$ balanço hídrico assim calculado torna-se um indicador climatológico da disponibilidade hídrica em uma região (Pereira et al., 1997), o que é fundamental no planejamento das atividades agrícolas.

Para Aguilar et al., (1986), os resultados de um balanço hídrico podem ser úteis no processo de zoneamento agroclimático de uma região, para o cálculo da demanda potencial de água das culturas irrigadas, na definição de prioridades no planejamento de pesquisas ou ainda, no conhecimento do regime hídrico. Nos cálculos do balanço

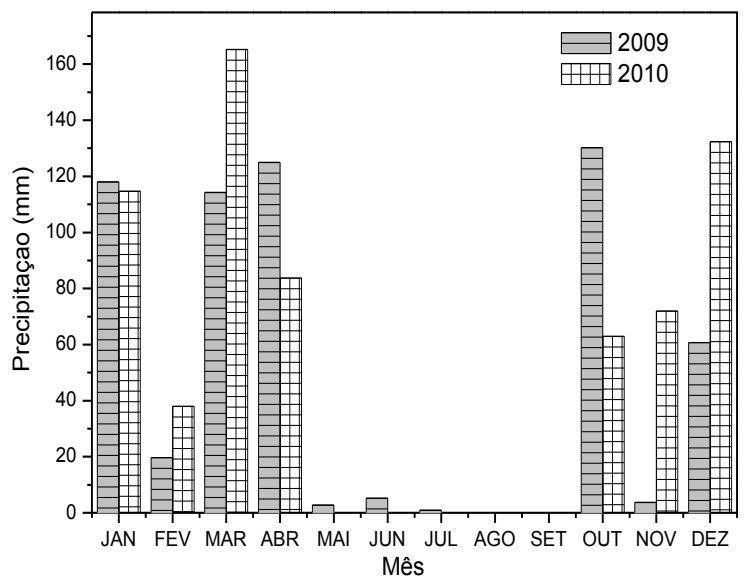

Figura 2- Índices pluviométricos registrados na Estação Irecê (período 2009 - 2010)

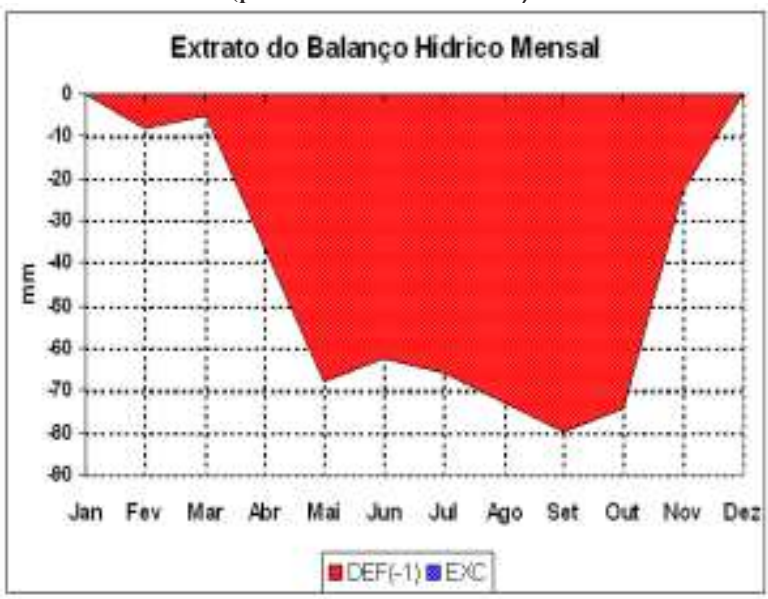

Figura 4- Extrato do balanço hídrico normal mensal do município de Irecê (período 1961 - 1990) hídrico, os valores de pluviometria representam o abastecimento de água para o aquífero, uma vez que a área não possui drenagens superficiais $\mathrm{e}$ como o aquífero é livre, pode-se considerar que a recarga nesse sistema é efetuada de forma direta.

Analisando as Figuras 2, 3, 4 e 5, pode-se observar que ocorre um déficit hídrico em todos os meses do ano na área, sobretudo entre os meses de abril e outubro, devido aos índices pluviométricos que são extremamente baixos, considerando-se uma média histórica, com valores médios de precipitação de $653,40 \mathrm{~mm} / \mathrm{ano}$. Essa situação, apenas não se verifica nos meses de dezembro e janeiro, em que ocorre uma certa reposição de água no aquífero, em função dos índices pluviométricos um pouco mais elevados no período, sem ocorrer, no entanto, excedente hídrico. A evapotranspiração, por sua vez, é elevada com um total de $1.147 \mathrm{~mm} / \mathrm{ano}$, notadamente na porção norte, em função do clima semi-árido da área.

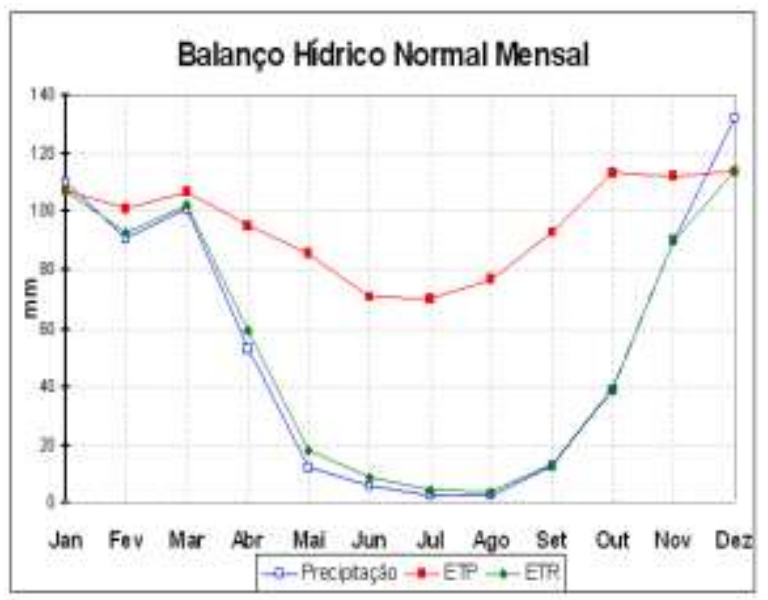

Figura 3- Balanço hídrico normal mensal do município de Irecê (período 1961 - 1990)

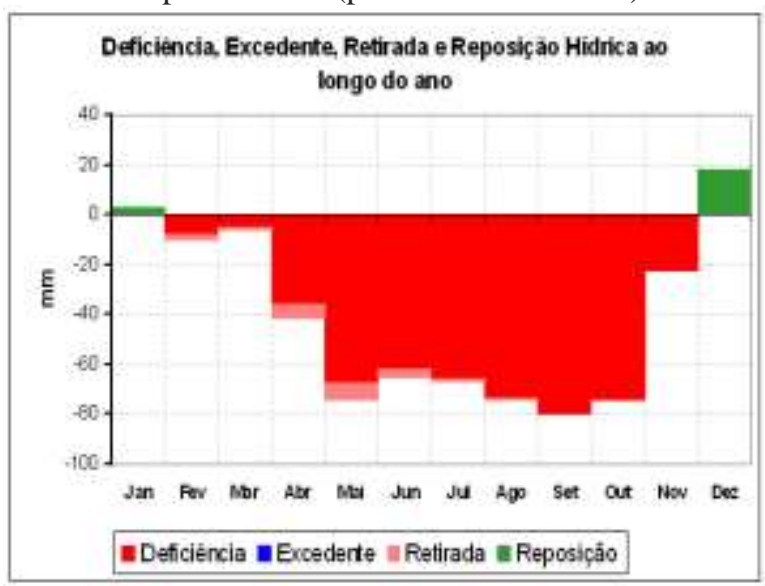

Figura 5 - Deficiência, excedente, retirada e reposição hídrica mensal do município de Irecê (período 1961 - 1990) 

O balanço hídrico climatológico foi realizado de acordo a média histórica obtida no período de (1961-1990), considerando as médias de temperatura e precipitação, através do método de THORNTHWAITE \& MATHER (1955).

A precipitação (P) no período foi de $653 \mathrm{~mm} /$ ano e a evapotranspiração potencial(ETP) foi da ordem de $1.147 \mathrm{~mm} /$ ano, representando $56,93 \%$ a mais do que o valor anual de precipitação pluviométrica. A deficiência hídrica foi de 494mm/ano, equivalendo a 75,65\% dos índices pluviométricos anuais, sem haver excedente hídrico.

\section{MATERIAIS E MÉTODOS}

As análises das amostras de água subterrânea coletadas foram realizadas no Laboratório de Águas Minerais da Companhia de Pesquisa de Recursos Minerais (LAMIN/CPRM), seguindo a metodologia descrita em SMEWW por CLESCERI et al., (1998).

Foram analisados um total de 72 parâmetros adotados para o diagnóstico hidroquímico da área, definidos de acordo com BRASIL (2004), que estabelece VMP (valores máximos permitidos) para padrões de potabilidade da água para consumo humano, e por BRASIL (2008), que estabelece VMP para diversas finalidades, além do consumo humano, como: dessedentação animal, irrigação e recreação (NOSSA, 2011).

\section{Análises físico-químicas das águas subterrâ- neas}

As análises físico-químicas foram realizadas considerando-se os cátions: alumínio, antimônio, arsênio. bário, berílio, boro, cádmio, cálcio, chumbo, cobalto, cobre, cromo, estanho, estrôncio, ferro, lítio, magnésio, manganês, molibdênio, níquel, potássio, selênio, silício, sódio, titânio, vanádio e zinco; além dos ânions: brometo, cloreto, fluoreto, fosfato, nitrato, nitrito e sulfato. Selecionou-se para análise também o carbonato e bicarbonato, em função da litologia carbonática da área e os parâmetros dureza total, condutividade elétrica, sólidos totais dissolvidos e $\mathrm{pH}$, perfazendo um total de 40 parâmetros físico-químicos analisados.

Para as análises dos ânions foi utilizado o método de Cromatografia Iônica e para as análises dos cátions foi utilizado o método ICP-OES. Os cátions e ânions analisados perfazem todos os elementos analisados pelo LAMIN, constantes em BRASIL (2004), para análise de potabilidade, de forma a possibilitar a determinação da qualidade da água na área.
Os cálculos hidroquímicos foram executados com o software PHREEQC, desenvolvido por Parkhurst \& Appelo (1999) e a representação gráfica dos resultados foi efetuada através de diagramas hidroquímicos.

\section{Análises de compostos orgânicos semi-voláteis nas águas subterrâneas}

Os compostos orgânicos semi-voláteis (agrotóxicos) analisados compreenderam 32 parâmetros, dentre os sugeridos por BRASIL (2004) e aqueles que são analisados pelo LAMIN: Hexaclorobenzeno, Lindano, Heptacloro, Heptacloro Epóxi, Aldrin, Dieldrin, Glifosato, Gamma-Clordano, Alpha-Clordano, 4,4-DDT, Endrin, Metoxicloro, Molinato, Trifluralina, Simazina, Propanil, Pendimetalina, Atrazina, Alacloro, Metacloro, Endosulfan-I, Endosulfan-II, Endosulfan Sulfato, Permetrina, 2,4,6Triclorofenol, 2,4-D, Pentaclorofenol, Bentazone, Clorotalonil, Melathion, Chlorpyrifos e PP-DDE. $\mathrm{O}$ preparo das amostras foi efetuado utilizando-se a técnica de Extração em Fase Sólida (SPE). A análise cromatográfica foi realizada pelo método de Cromatografia Gasosa acoplada a Espectometria de Massas (GC-MS). O equipamento utilizado foi um GC-MS 4000 Varian.

\section{Análises granulométricas de solos}

As análises granulométricas foram realizadas no Laboratório de Estudos Costeiros da Universidade Federal da Bahia (LEC/UFBA), em 17 amostras de solos coletados em pontos selecionados da rede de monitoramento de água a $50 \mathrm{~cm}$ de profundidade. Foi utilizado o peneiramento a seco e quarteamento das amostras. Em seguida, foi retirada uma alíquota do material preparado e colocado no granulômetro a laser Horiba LA 950.

\section{Análise de metais nos solos}

Foram realizadas análises de metais em 07 amostras de solo coletadas em campo com trado manual a $50 \mathrm{~cm}$ de profundidade. Os metais $\mathrm{Cu}^{+2}, \mathrm{Zn}^{+2}, \mathrm{~Pb}^{+2}, \mathrm{Fe}^{+2}$ e $\mathrm{Ni}^{+2}$, foram selecionados para extração no Laboratório de Estudos do Petróleo da Universidade Federal da Bahia (LEPETRO/UFBA). Os locais selecionados para amostragem foram os mais propensos à contaminação como lixões, áreas de disposição de rejeitos de mineração e áreas urbanas. A extração das amostras seguiu a metodologia preconizada por ASTM D 5258, (1996). 


\section{RESULTADOS}

\section{Balanço hídrico climatológico}

O cálculo do índice hídrico (IH) pode ser calculado de acordo com a equação de THORNTHWAITE \& MATHER (1955):

$$
\mathrm{IH}=\frac{100 . \mathrm{EXC}-60 . \mathrm{DEF}}{\mathrm{ETP}}
$$

Considerando-se os dados históricos do balanço hídrico climatológico (Figura2), tem-se que $\mathrm{IH}=-25,84$. Esse valor expressa o predomínio da evapotranspiração potencial em 56,93\% em relação aos dados de precipitação anual $(653 \mathrm{~mm})$, implicando em uma deficiência hídrica de 494mm/ano, característica de clima semi-árido.

\section{Análises físico-químicas}

Os elementos que apresentam valores acima dos limites máximos permitidos para potabilidade, de acordo com BRASIL (2004; 2008), considerando-se também (W.H.O., 2003), para o cálcio $(75,0 \mathrm{mg} / \mathrm{l})$ e magnésio $(50,0 \mathrm{mg} / \mathrm{l})$, não constantes nas legislações supracitadas; foram listados, considerando-se a sua ocorrência em relação ao percentual de amostras analisadas: cálcio $(100,00 \%)$, magnésio $(50,00 \%)$, dureza total $(52,82 \%)$, sólidos totais dissolvidos $(11,12 \%)$, fluoreto $(5,56 \%)$, cloreto $(13,9 \%)$, nitrito $(2,78 \%)$, nitrato $(83,4 \%)$ e sulfato $(5,56 \%)$.

\section{Análises de compostos orgânicos semi-voláteis (agrotóxicos)}

As análises dos 32 compostos orgânicos semi-voláteis (agrotóxicos) efetuadas demonstraram que em todas as amostras coletadas, não fo-

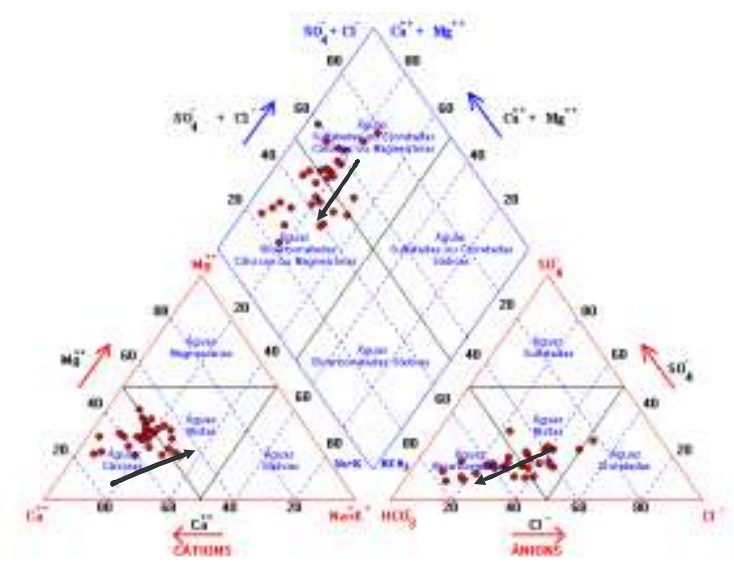

Figura 6- Diagrama de Piper mostrando o comportamento químico das águas subterrâneas do aquífero Salitre em 2009 ram detectados os compostos pesquisados. A não detecção dos compostos semi-voláteis nas análises realizadas significa que esses compostos podem se encontrar em quantidades muito reduzidas e, portanto, não detectáveis ou mesmo ausentes no momento da coleta, uma vez que o sistema de fraturamentos da área, juntamente com os condutos formados por processos de dissolução de $\mathrm{CaCO}_{3}$, propiciam a formação de regimes de fluxo, ora turbulentos, ora laminares no interior destas cavidades, que possibilita uma circulação mais rápida do fluxo nesses sistemas.

A área de Irecê é caracterizada, fundamentalmente, por propriedades tipo minifúndios, nas quais é praticada a agricultura de subsistência por uma população, em geral, com baixo poder aquisitivo. Essa situação implica na não aplicação ou no uso insipiente de fertilizantes e agrotóxicos, o que também contribui com a não detecção de compostos semi-voláteis nas águas dos poços tubulares pesquisados durante o período de coleta na área.

\section{Classificação de Piper}

A análise dos diagramas referentes às campanhas de 2009 (Figura 6) e 2010 (Figura 7) demonstra que das amostras analisadas 51,62\% são caracterizadas como águas Bicarbonatadas Cálcicas e Mistas e 48,38\% apresentam características de águas Cloretadas Cálcicas e Mistas. As setas ilustradas nos diagramas demonstram o posicionamento dos pontos de coleta em relação às direções de fluxo subsuperficiais, permitindo constatar que no sentido do fluxo as águas tendem a passar de Cloretadas Cálcicas à Bicarbonatadas Cálcicas, de acordo com NOSSA et al., (2011).

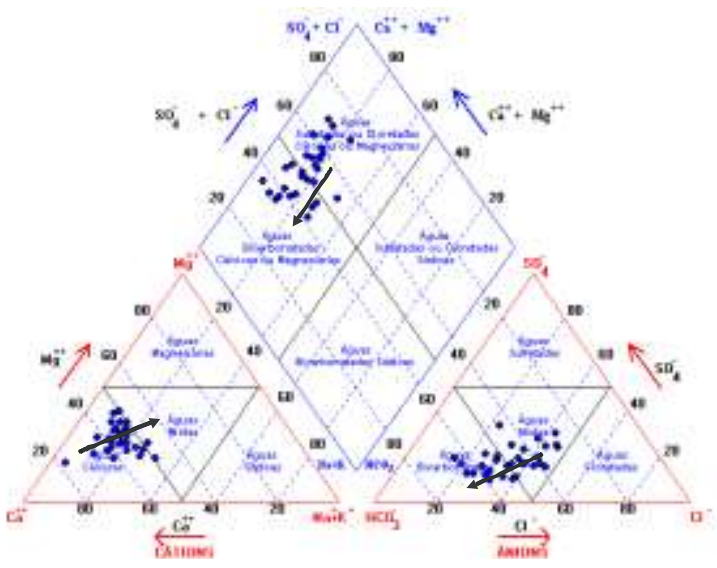

Figura 7- Diagrama de Piper mostrando o comportamento químico das águas subterrâneas do aquífero Salitre em 2010 


\section{Classificação de Lemoine}

A análise dos gráficos permite verificar que, tanto na campanha de 2009 , como na campanha de 2010, das 36 amostras analisadas, 32 foram classificadas como $\mathrm{C}_{3} \mathrm{~S}_{1}$ - água de alta salinidade e baixa concentração de sódio e apenas 04 amostras foram classificadas como $\mathrm{C}_{4} \mathrm{~S}_{1}$ - água de muito alta salinidade e baixa concentração de sódio; apresentando portanto, como constatado por Nossa (2011), alto a muito alto risco de

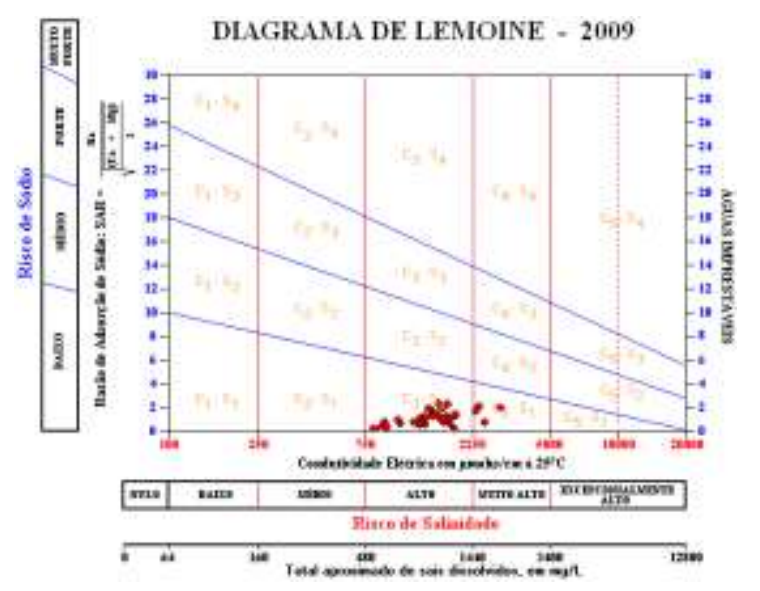

Figura 8- Diagrama de Lemoine mostrando o comportamento das águas subterrâneas para a finalidade agrícola coletadas no aquífero Salitre em 2009

\section{Análise granulométrica dos solos}

Os solos são caracterizados fundamentalmente como Cambissolos Háplicos Eutróficos, com ocorrência em toda a área e,secundariamente, ocorrem Latossolos Vermelhos Eutróficos associados às áreas de topografia um pouco mais elevada. São caracterizados como solos rasos, desenvolvidos em relevos planos a suavemente ondulados e constituídos por material mineral, com horizonte B incipiente ou câmbico, não hidromórfico, com pequena diferenciação de textura do horizon- salinização, o que significa que os solos da área devem ser bem drenados e mesmo assim podem ser necessárias práticas especiais de controle da salinidade, apresentando pequena probabilidade de alcançar níveis perigosos de sódio trocável, ou seja, são associados a baixo risco de sodificação (Figuras 8 e 9).

$$
\operatorname{RAS}=\frac{\mathrm{Na}^{+}}{\sqrt{\mathrm{Ca}^{++}+\mathrm{Mg}^{++}}}
$$

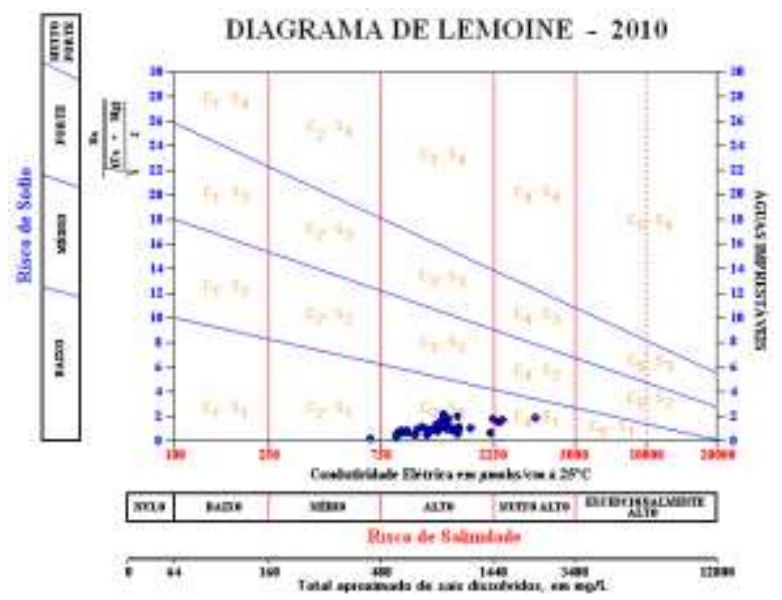

Figura 9- Diagrama de Lemoine mostrando o comportamento das águas subterrâneas para a finalidade agrícola coletadas no aquífero Salitre em 2010

te A para o horizonte $\mathrm{B}$, sendo desenvolvidos a partir dos calcários da Formação Salitre, Grupo Una (EMBRAPA, 2006).

A análise da Figura 10 permite constatar que os solos da área apresentam valores médios de granulometria caracterizados por partículas tamanho silte $(60,82 \%)$, areia $(22,26 \%)$ e argila $(16,92 \%)$. 


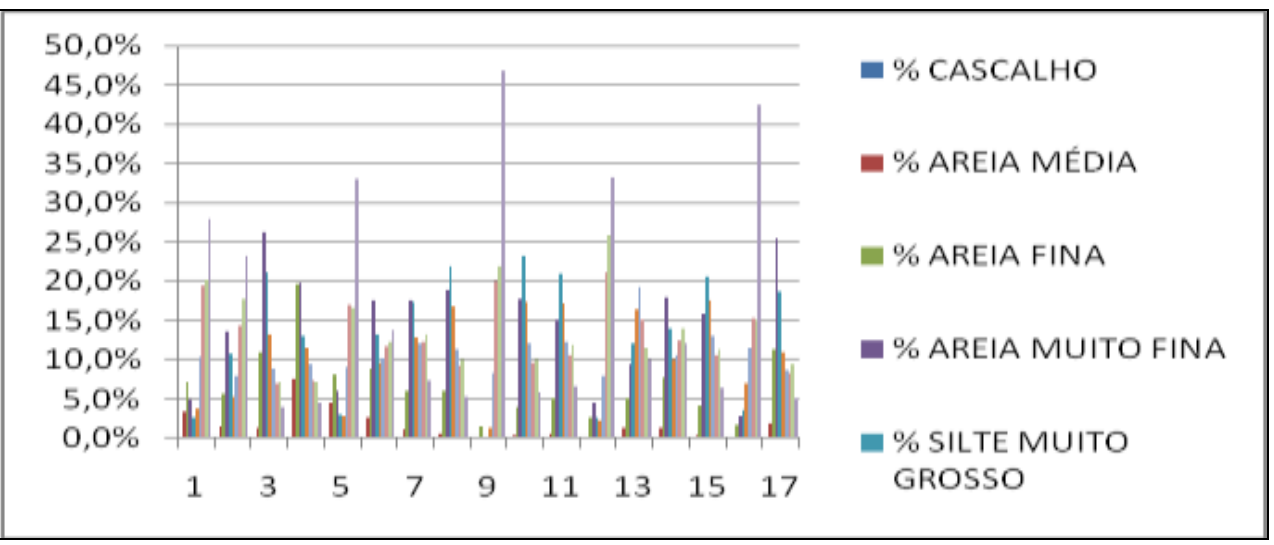

Figura 10 - Representação gráfica das análises granulométricas de amostras de solo coletados

\section{Análise de metais nos solos}

Foram selecionados para análise no Laboratório de Estudos do Petróleo da Universidade Federal da Bahia (LEPETRO/UFBA), os metais: $\mathrm{Cu}^{+2}, \mathrm{Zn}^{+2}, \mathrm{~Pb}^{+2}, \mathrm{Fe}^{+2}$ e $\mathrm{Ni}^{+2}$, em função do teor elevado sobretudo de $\mathrm{Zn}^{+2}$ e $\mathrm{Pb}^{+}$em ocorrências minerais na área, de forma a verificar a possível ocorrência desses elementos no solo. A análise das Tabelas 1 e 2 permite constatar que os valores obtidos nas análises de metais nos solos coletados são inferiores aos valores orientadores de acordo com BRASIL (2009), com exceção da amostra S-16, coletada em área de disposição de rejeitos de mineração, onde foi observado valores de chumbo elevados, para a finalidade de uso agrícola, podendo ter origem natural, em função das mineralizações de chumbo que ocorrem na área.

Tabela 1- Resultados das análises de metais obtidos em amostras de solos coletados na área (NOSSA, 2011)

\begin{tabular}{|c|c|c|c|c|c|c|c|}
\hline \multirow{4}{*}{ LOCALIDADES } & \multirow{4}{*}{ AMOSTRAS } & PARÂMETROS & $\begin{array}{l}\text { Cobre } \\
(\mathrm{mg} / \mathrm{Kg})\end{array}$ & $\begin{array}{c}\text { Zinco } \\
(\mathrm{mg} / \mathrm{Kg})\end{array}$ & $\begin{array}{l}\text { Chumbo } \\
\text { (mg/Kg) }\end{array}$ & $\begin{array}{c}\text { Ferro } \\
(\%)\end{array}$ & $\begin{array}{l}\text { Níquel } \\
(\mathbf{m g} / \mathbf{K g})\end{array}$ \\
\hline & & MÉTODO & SWEMM & SWEMM & SWEMM & SWEMM & SWEMM \\
\hline & & LQP (mg/Kg) & $\mathbf{0 , 3 5}$ & 0,47 & 2,5 & $\mathbf{0 , 0 3}$ & 2,5 \\
\hline & & $\begin{array}{c}\text { Data da Análise } \\
\text { (LEPETRO/UFBA) }\end{array}$ & \multicolumn{5}{|c|}{$\begin{array}{c}\text { RESULTADOS } \\
\text { (LEPETRO / UFBA) }\end{array}$} \\
\hline Lixão de Lapão & S-4.1 & $15 / 09 / 2010$ & 11,36 & 43,35 & 109,6 & 5,26 & 17,3 \\
\hline Lixão de Lapão & S-4.2 & $15 / 09 / 2010$ & 9,63 & 39,36 & 81,4 & 4,96 & 15,7 \\
\hline $\begin{array}{l}\text { Rodovia Irecê- } \\
\text { Lapão (Km-05) }\end{array}$ & S-8 & $15 / 09 / 2010$ & 30,96 & 43,12 & 48,2 & 7,72 & 49,6 \\
\hline $\begin{array}{l}\text { Zona urbana - } \\
\text { Lapão }\end{array}$ & S-10 & $15 / 09 / 2010$ & 7,66 & 15,13 & 16,2 & 1,07 & 14,9 \\
\hline $\begin{array}{l}\text { Área de disposi- } \\
\text { ção de rejeitos } \\
\text { de mineração }\end{array}$ & S-16.1 & $15 / 09 / 2010$ & 25,11 & 49,21 & 227,9 & 9,86 & 35,9 \\
\hline $\begin{array}{l}\text { Área de disposi- } \\
\text { ção de rejeitos } \\
\text { de mineração }\end{array}$ & S-16.2 & $15 / 09 / 2010$ & 32,66 & 43,75 & 242,8 & 8,86 & 53,2 \\
\hline Zona urbana - & S-19 & $15 / 09 / 2010$ & 16,53 & 37,61 & 15,8 & 4,43 & 27,3 \\
\hline Lixão de Irecê & S-20.1 & $15 / 09 / 2010$ & 12,23 & 16,65 & $<\mathrm{LDM}$ & 2,95 & 19,2 \\
\hline Lixão de Irecê & S-20.2 & $15 / 09 / 2010$ & 10,68 & 10,94 & $<\mathrm{LDM}$ & 2,43 & 17,3 \\
\hline $\begin{array}{c}\text { Povoado de Meia } \\
\text { Hora }\end{array}$ & S-23 & $15 / 09 / 2010$ & 23,41 & 34,07 & $<\mathrm{LDM}$ & 6,16 & 28,8 \\
\hline $\begin{array}{l}\text { LQP: Limite de Quant } \\
\text { exatidão, pelo método } \\
\text { LDM: Limite de Detec }\end{array}$ & $\begin{array}{l}\text { cação Praticável: } \\
\text { lizado (BRASIL } \\
\text { no do Método: m } \\
008 \text { ). }\end{array}$ & $\begin{array}{l}\text { enor concentração de u } \\
\text { 008). } \\
\text { or concentração de uma }\end{array}$ & substância & pode ser de & minada quar & ativamente & n precisão e \\
\hline
\end{tabular}


Tabela 2- Valores orientativos, de acordo com BRASIL (2009), para solos considerando-se os usos: agrícola, residencial e industrial (NOSSA, 2011)

\begin{tabular}{|c|c|c|c|}
\hline \multicolumn{4}{|c|}{$\begin{array}{l}\text { USO PREPONDERANTE DOS SOLOS } \\
\text { (BRASIL, 2009) }\end{array}$} \\
\hline PARÂMETROS & \multicolumn{3}{|c|}{$\begin{array}{l}\text { VALORES ORIENTADORES } \\
\text { (mg/kg de peso seco) }\end{array}$} \\
\hline TNVESTIGACÃO & AGRÍCOLA & RESIDENCIAL & INDUSTRIAL \\
\hline Cobre (mg/Kg) & 200 & 400 & 600 \\
\hline Zinco (mg/Kg) & 450 & 1000 & 2000 \\
\hline Chumbo (mg/Kg) & 180 & 300 & 900 \\
\hline Níquel (mg/Kg) & 70 & 100 & 130 \\
\hline Ferro $(\%)$ & -- & -- & -- \\
\hline
\end{tabular}

\section{Mapa de declividade}

O Mapa de Declividade da área (Figura 11), foi elaborado em escala 1:25.000, com base no modelo digital de terreno (MDT), a partir de imagens de radar SRTM (Shuttle Radar Topography Mission) e levantamento da rede de 36 poços desativados para medida de nível estático e das cotas de cada poço em relação à base do terreno, capturados com GPS diferencial (DGPS), em trabalhos de campo.

A análise da Figura 11, permite constatar que a área possui declividades bastante suaves, predominando as classes com declividades inferiores a $8 \%$ que perfazem, aproximadamente, $94 \%$ da área, caracterizando o domínio geomorfológico denominado de Chapada de Irecê, com topografia plana a suavemente ondulada e elevações suaves. As declividades inter- mediárias são subdivididas em classes que variam de $8 \%$ a $20 \%$ e constituem $5,4 \%$ da área. $\mathrm{O}$ equivalente a aproximadamente $0,6 \%$ do restante da área, é constituído por declividades superiores a 20\%. A análise do Mapa de Declividade permite constatar, portanto, que a topografia plana a suavemente ondulada da área, propicia o predomínio de processos de infiltração sobre os processos de escoamento superficial, contribuindo com um maior aporte hídrico para o aquífero cárstico Salitre que, no entanto, permanece com um déficit hídrico de aproximadamente $494 \mathrm{~mm} / \mathrm{ano}$, equivalendo a cerca de $75,65 \%$ dos índices pluviométricos anuais, sem haver excedente hídrico, em função das precipitações escassas e irregulares que caracterizam o clima semi-árido na área. 


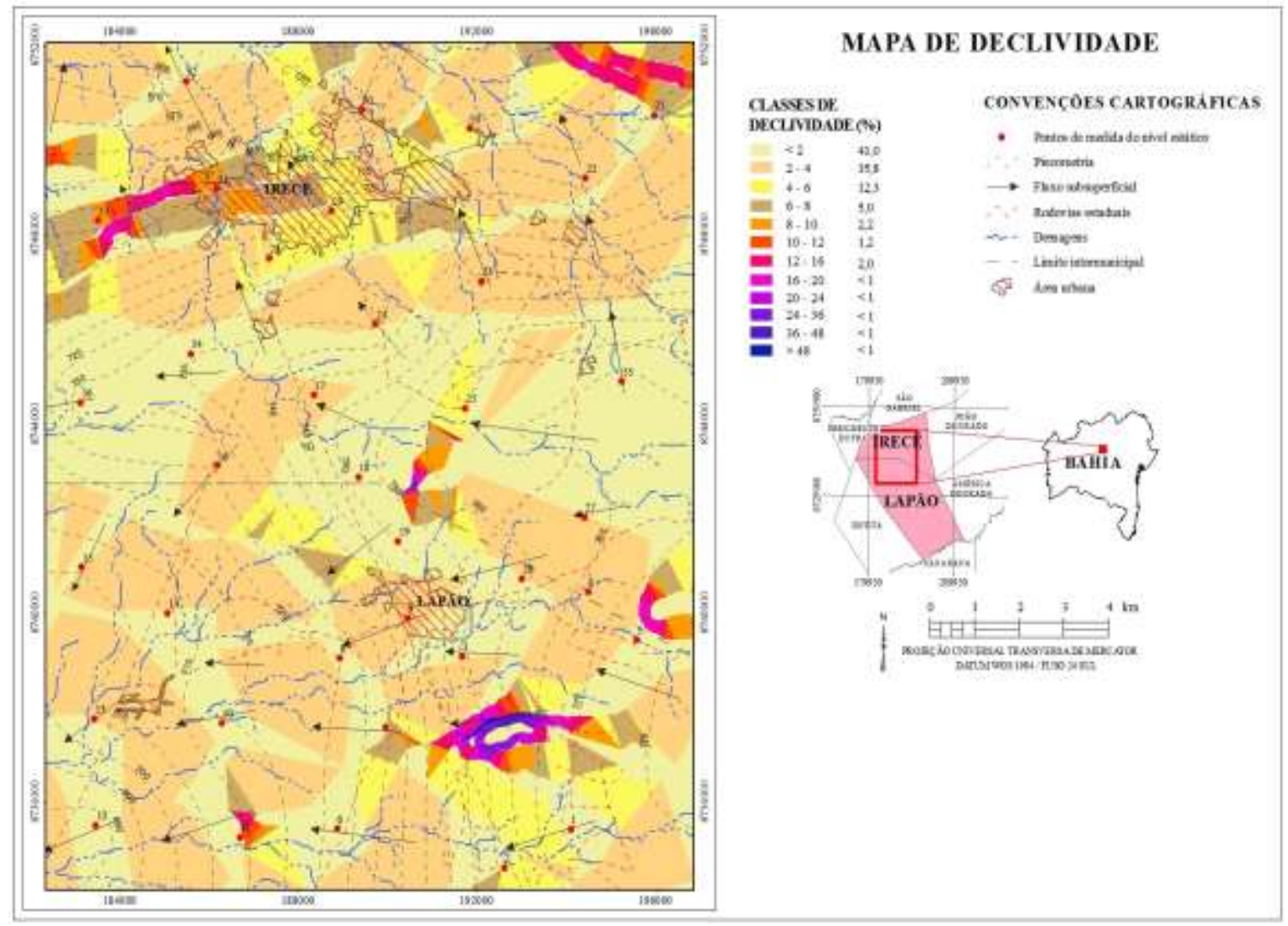

Figura 11- Mapa de Declividade

\section{Mapa de uso e ocupação dos solos}

O Mapa de Uso e Ocupação dos Solos da área (Figura 12), foi produzido em escala 1:25.000, através do levantamento das classes de uso e ocupação dos solos, realizado em trabalhos de campo com a utilização de GPS e composição das feições com o tratamento de imagens AVNIR2/ALOS (IBGE, 2007), com resolução de 10m x $10 \mathrm{~m}$, utilizando-se o software ENVI 4.5.

A elaboração do Mapa de Uso e Ocupação dos Solos, possibilitou a delimitação de classes de uso e ocupação subdivididas da seguinte maneira: Agropecuária $(75,70 \%)$, Cobertura Vegetal Nativa $(17,41 \%)$, Área Urbanizada $(4,36 \%)$, Áreas de Mineração $(2,48 \%)$ e Lixões $(0,05 \%)$, (Figura 12).

A análise do Mapa de Uso e Ocupação dos Solos permite constatar que a cidade de Irecê apresenta vetores de crescimento preferenciai no setor sul, em direção à BA-432, no sentido da cidade de Lapão e nos setores N/NE, em direção ao povoado de Meia Hora e N/NW em direção à cidade de Xique-Xique. Por sua vez, a cidade não apresenta vetores de crescimento nos setores SW, em função da presença do lixão e SE, devido às áreas de mineração. A cidade de Lapão apresenta vetores de crescimento preferenciais na direção E$\mathrm{W}$ ao longo da BA-433 e ao norte, ao longo da BA-432, em direção à cidade de Irecê, no setor sul da cidade o vetor de crescimento é inibido em função da presença do lixão. Dessa forma, o Mapa de Uso e Ocupação dos Solos pode ser utilizado pelos gestores municipais para compatibilizar os vetores de crescimento das cidades de Irecê e Lapão com as atividades desenvolvidas na área. 


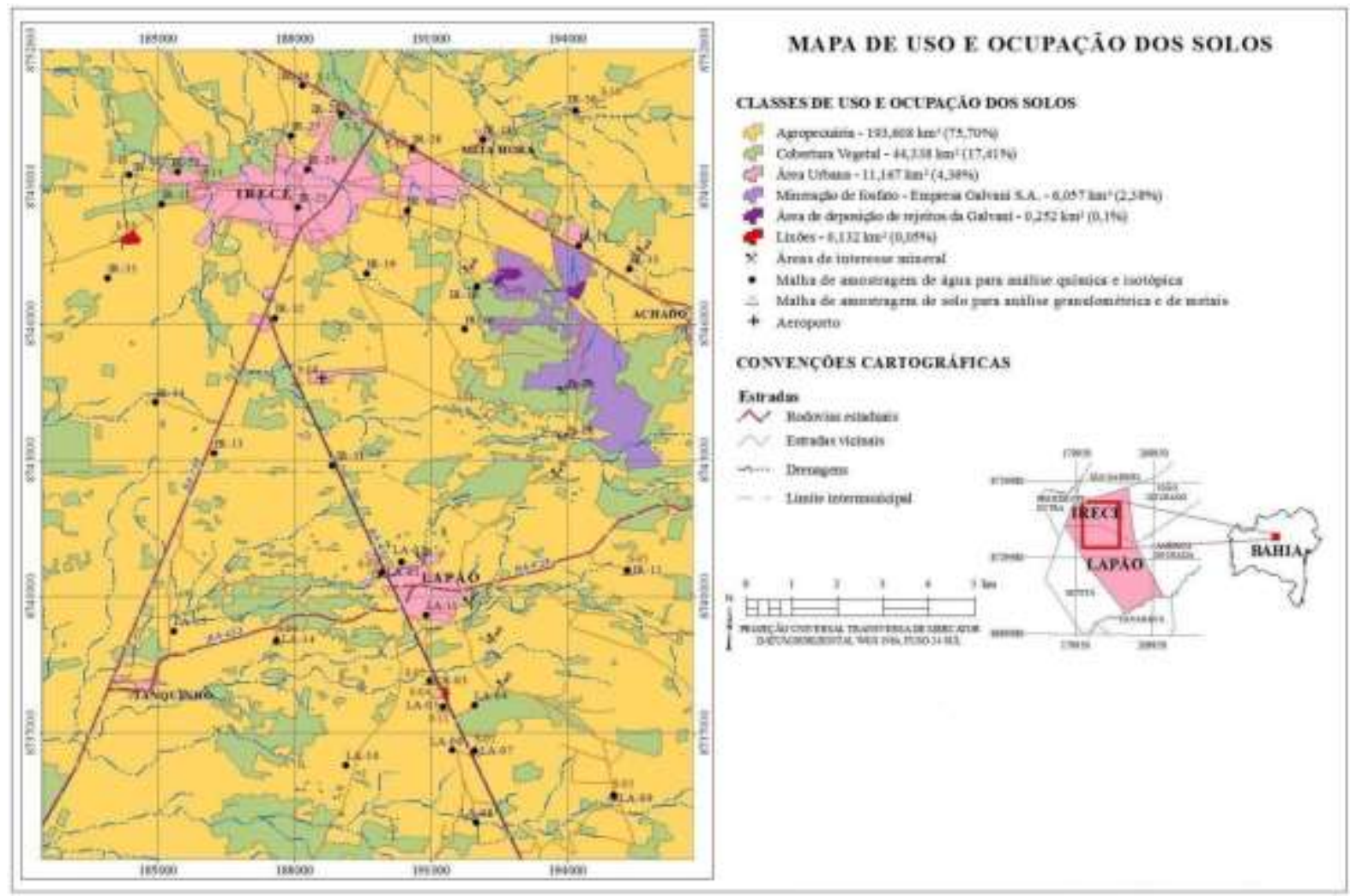

Figura 12- Mapa de Uso e Ocupação dos Solos

\section{CONCLUSÕES}

A análise da água utilizada para a finalidade de irrigação permitiu verificar que nas duas campanhas efetuadas, $89 \%$ das águas subterrâneas analisadas foram classificadas como $\mathrm{C}_{3} \mathrm{~S}_{1}$ - água de alta salinidade e baixa concentração de sódio e apenas $11 \%$ das amostras analisadas foram classificadas como $\mathrm{C}_{4} \mathrm{~S}_{1}$ - água de muito alta salinidade e baixa concentração de sódio. As amostras de água analisadas apresentaram, portanto, alto a muito alto risco de salinização, o que significa que os solos da área devem ser bem drenados e mesmo assim, podem ser necessárias práticas especiais de controle da salinidade, aliado a uma pequena probabilidade de alcançar níveis perigosos de sódio trocável, ou seja, são associados a baixo risco de sodificação.

Dessa forma, as águas classificadas como $\mathrm{C}_{3} \mathrm{~S}_{1}$, podem ser normalmente utilizadas para projetos de irrigação e as águas classificadas como $C_{4} S_{1}$, não devem ser utilizadas para irrigação, em função do perigo de salinização dos solos.

A agricultura irrigada efetuada através da utilização de sistemas de irrigação com captação de água em poços tubulares se constitui em uma alternativa de produção para viabilizar melhorias socioeconômicas, uma vez que apresenta um menor risco em relação à escassez e à irregularidade de chuvas da região.

A análise granulométrica dos solos coletados em 17 pontos de amostragem permitiu a caracterização textural dos solos na área como silto-arenoso (41,18\%), silto-argiloso $(35,29 \%)$ e siltoso $(23,53 \%)$. Foi constatado que os valores obtidos nos metais analisados: $\mathrm{Cu}^{+2}, \mathrm{Zn}^{+2}, \mathrm{~Pb}^{+2}$, $\mathrm{Fe}^{+2}$ e Ni $^{+2}$, nos solos coletados são inferiores aos valores orientadores da BRASIL (2009), com exceção da amostra S-16, coletada na área de disposição de rejeitos de mineração, em que foi detectado teor de chumbo de $242,8 \mathrm{mg} / \mathrm{kg}$, considerado elevado para a finalidade de uso agrícola, podendo contudo, ser utilizado para as finalidades de uso residencial e industrial. A ocorrência do chumbo pode ter origem natural, em função das mineralizações que ocorrem na área.

O diagnóstico da distribuição das classes obtidas no Mapa de Uso e Ocupação na área permite verificar que predomina a classe de Agropecuária, sobretudo as atividades agrícolas, que são as grandes responsáveis pela receita dos municípios de Irecê e Lapão. 
O percentual de análises físico-químicas acima dos valores máximos permitidos (VMP) de acordo com as legislações aplicáveis, para os seguintes elementos: cálcio $(100,00 \%)$, dureza total $(75,06 \%)$, magnésio $(69,00 \%)$, sólidos totais dissolvidos $(22,24 \%)$, sulfato $(5,56 \%)$ e fluoreto $(5,56 \%)$, retratam as condições naturais do aquífero cárstico Salitre na área. A ocorrência de nitrato $(83,4 \%)$ e nitrito $(2,78 \%)$ pode ter origem natural, oriundos do excesso de matéria orgânica

no ambiente ou antropogênica, devido à contaminação ocasionada por saneamento básico inadequado ou ainda, em função do uso intensivo de fertilizantes nitrogenados. A detecção de cloreto $(16,68 \%)$ pode ser associada à deficiência na circulação hídrica subterrânea ou a focos esparsos de contaminação. A ocorrência do arsênio $(8,33 \%)$, presente de forma pontual nas águas subterrâneas, pode estar relacionada à utilização inadequada de defensivos agrícolas nas culturas da área.

$\mathrm{Na}$ análise dos compostos semi-voláteis (agrotóxicos), selecionados de acordo com as legislações aplicáveis, foi constatada a não detecção desses compostos, significando que estes podem não ocorrer na área ou estar presentes em quantidades muito reduzidas e, portanto, não detectáveis no momento da coleta, uma vez que o sistema de fraturamentos, juntamente com os condutos formados por processos de dissolução de $\mathrm{CaCO}_{3}$ na área, propiciam uma circulação rápida do fluxo nesses sistemas. Aliado ao fato de que,

\section{REFERENCIAS}

AGUILAR, D. J.; KRUKER, R. J. M.; CALHEIROS, R. O. Determinação da evapotranspiração potencial e balanço hídrico da região da Grande Dourados. Dourados: EMBRAPA-UEPAE. 1986. 150 p.

ASTM. American Society for Testing Materials. Standard pratice for acid-extraction of elements from sediments using closed vessel microwave heating. 5258 - 92 (Reapproved). p.740-742. 1996.

AYRES, R. S.; WESTCOT, D. W. Water quality for agriculture. Roma: FAO. Irrigation and Drainage Paper, 29, Rev. 1. 1985. $174 \mathrm{p}$

BRASIL. Ministério da Saúde. Portaria n518/MS, de 25 de março de 2004. Estabelece os procedimentos e responsabilidades relativos ao controle e vigilância da qualidade da água para consumo humano e seu padrão de potabilidade, e dá outras providências. Legislação. Disponível em: http://portal.saude.gov.br/saude/. Acesso em 15.02.2009.

BRASIL. Conselho Nacional do Meio Ambiente - CONAMA. Resolução 357, de 17 de março de 2005. Dispõe sobre a classificação dos corpos de água e diretrizes ambientais para o seu enquadramento, bem como estabelece as condições e as propriedades na área são caracterizadas essencialmente por minifúndios com a prática da agricultura de subsistência, o que implica em uma utilização minimizada desses insumos.

A análise dos diagramas de Piper demonstra que $51,62 \%$ das amostras analisadas são caracterizadas como águas Bicarbonatadas Cálcicas e Mistas e 48,38\% apresentam características de águas Cloretadas Cálcicas e Mistas. Dessa forma, foi constatado um certo equilíbrio entre a qualidade das águas analisadas. Esse diagnóstico é corroborado pelos dados históricos das águas subterrâneas obtidos em toda a Bacia de Irecê. Essa constatação indica que a qualidade das águas subterrâneas na área se manteve sem grandes alterações ao longo dos últimos 30 anos.

\section{AGRADECIMENTOS}

Os autores agradecem ao Serviço Geológico do Brasil (CPRM) pelo apoio nos trabalhos de campo e na realização das análises físicoquímicas e de compostos semi-voláteis no Laboratório de Águas Minerais (LAMIN/CPRM/RJ); ao Laboratório de Estudos Costeiros da Universidade Federal da Bahia (LEC/UFBA) pelas análises granulométricas dos solos e ao Laboratório de Estudos do Petróleo da Universidade Federal da Bahia (LEPETRO/UFBA) pelas análises de metais no solo.

padrões de lançamento de efluentes, e dá outras providências. Disponível em: http://conama.gov.br. Acesso em 25.09.2010.

BRASIL. Conselho Nacional do Meio Ambiente - CONAMA. Resolução 420, de 28 de dezembro de 2009. Dispõe sobre critérios e valores orientadores de qualidade do solo quanto à presença de substâncias químicas e estabelece diretrizes para o gerenciamento ambiental de áreas contaminadas por essas substâncias em decorrência de atividades antrópicas. Disponível em: http://conama.gov.br. Acesso em 20.05.2010.

CLESCERI, L. S.; GREENBERG, A. E.; EATON, A. D. Standard methods for the examination of water and wastewater. $20^{\text {th }}$ ed. American Public Health Association, Washington. 1998. 1325 p. ISBN 0875532357.

EATON, F. M. Significance of carbonates in irrigation waters. Soil Science, v. 60, p. 123-133. 1949.

EMBRAPA. Centro Nacional de Pesquisa de Solos.Sistema Brasileiro de Classificação de Solos. Rio de Janeiro, 2 ed., EMBRAPA-SP. 2006.

EMBRAPA. Centro Nacional de Pesquisa de Solos. Monitoramento por satélite - Banco de Dados Climáticos do Brasil. 
Disponível

http://www.bdclima.cnpm.embrapa.br/referencia.php. Acesso em 25.09.2010. 2003.

IBGE. Instituto Brasileiro de Geografia e Estatística. Imagem AVNIR-2 / ALOS. Disponível em: http://www.ibge.gov.br/alos//. Acesso em: 10.01.2009. 2007.

NOSSA, T. C. B. Avaliação da vulnerabilidade do aquífero cárstico Salitre - Bahia, através de análises hidroquímicas, isotópicas e aplicação da metodologia COP. Salvador, Bahia, Brasil, 226p. 2011. Tese (Doutoramento em Geologia). Universidade Federal da Bahia.

NOSSA, T. C. B.; BASTOS LEAL, L. R.; ZUCCHI, M. do R. Hidroquímica e índices de saturação dos minerais do sistema aquífero cárstico Salitre na região de Irecê-Lapão, Bahia, Brasil. Anais in: II Congresso Internacional de Meio Ambiente Subterrâneo, São Paulo-SP. 2011.

PARKHURST, D. L.; APPELO, C. A. J. User's guide to PHREEQC (Version2): a computer program for especiation, batch-reaction, one-domensional transport and inverse geochemical calculations. US Geol. Survey, Water Resourch Investig. Rep. 99-4259. 1999.

PEDREIRA, A. J.; ROCHA, A. J. D.; COSTA, I. V. G. da; MORAIS FILHO, J. C. Projeto Bacia de Irecê-II: Relatório Final. Salvador, CPRM. 1987.

PEREIRA, A. R.; VILLA NOVA, N. A.; SEDIYAMA, G. C. Evapotranspiração. Piracicaba: FEALQ, 1997. 183p.

THORNTHWAITE, C. W.; MATHER, J. R. The water balance. New Jersey: Drexel Institute of Technology. 1955, $104 \mathrm{p}$.

YARON, B. Water suitability for irrigation. In: YARON, E.; DANFORS, E.; VAADID, Y. (Eds.) Arid zone irrigation, Berlin: Springler-Verlag. Cap. 4, p. 71-85. Ecological Studies, 5. 1973.

W.H.O. World Health Organization. Guidelines for drinkingwater quality. 3nd. V.1., Recommendations. Addendum. Geneva. 2003. 